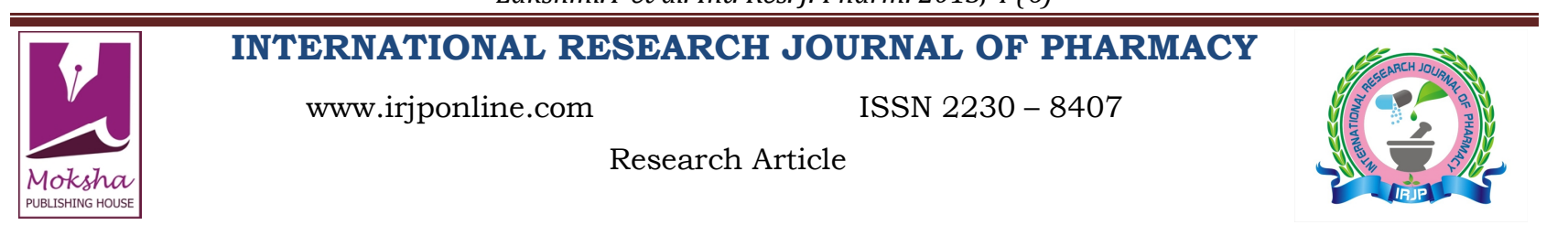

\title{
EVALUATION OF HEAVY METALS IN ETHANOLIC LEAF EXTRACT OF ACACIA CATECHU AS INDICATOR OF POLLUTION BY ATOMIC ABSORPTION SPECTROPHOTOMETRIC (FAAS) ANALYSIS
}

\author{
Lakshmi. $T^{1 *}$, Rajendran. $\mathrm{R}^{2}$, Antony silvester ${ }^{3}$ \\ ${ }^{1}$ Reader, Department of Pharmacology, Saveetha Dental College and Hospitals, Chennai, India \\ ${ }^{2}$ C.E.O, Green Chem Herbal extract and formulations, Bangalore, India \\ ${ }^{3}$ Quality control Analyst, Natysan catalysts, Nammakal, India \\ *Corresponding Author Email: 1akshmi085@gmail.com
}

Article Received on: 17/03/13 Revised on: 01/04/13 Approved for publication: 01/05/13

DOI: $10.7897 / 2230-8407.04624$

IRJP is an official publication of Moksha Publishing House. Website: www.mokshaph.com

(C) All rights reserved.

\section{ABSTRACT}

Acacia catechu ethanolic leaf extract were selected to determine their heavy metals content and thereby to assure their safer therapeutic application. The trace and heavy metals were detected through atomic absorption spectrometry analysis. The selected medicinal plant material was procured from green chem herbal extracts, Bangalore, India and was digested with nitric acid and hydrochloric acid as specified. Absorbance was measured through atomic absorption spectrometer (AA 6030) and the concentration of different heavy metals in the plant sample was calculated. The quantitative determinations were carried out using standard calibration curve obtained by the standard solutions of different metals. The contents of heavy metals were found to be within the prescribed limit. Thus, on the basis of experimental outcome, it can be concluded that the plant material is safe and may not produce any harmful effect of metal toxicity during their therapeutic application. The investigated medicinal plants contains heavy metals such as arsenic ( $\mathrm{As})$, lead ( $\mathrm{Pb})$ and mercury ( $\mathrm{Hg})$ and cadmium (Cd), which were present within the permissible limit.

Keywords: Acacia catechu, leaves, heavy metals, pollution.

\section{INTRODUCTION}

In the environment, heavy metal pollutants are released from many different anthropogenic sources. ${ }^{1}$ Heavy metals are released in the form of atmospheric particulates in different sizes which may be found as very minute solid, liquid and gaseous particles. Depending upon the geographical sources heavy metals and trace elements may differ which may lead to severe toxicity. These Particulate matters are produced during the incomplete combustion of diesel fuel. It has been shown that diesel engines, which power most of the nation's transportation (buses, trains, ships, cars, trucks) produce tones of air pollutants and account for more than two-thirds of all particulate matter from transportation sources. ${ }^{2}$ Lead and cadmium are among the most abundant heavy metals and are particularly toxic. ${ }^{3}$ Excessive content of these metals in food is associated with a number of diseases, especially of the cardiovascular, renal, nervous and skeletal systems. ${ }^{4-6}$ These heavy metals are also implicated in carcinogenesis, mutagenesis and teratogenesis. Other metals, such as copper and zinc are essential for important biochemical and physiological functions and necessary for maintaining health throughout life. Acacia catechu commonly known as karungali in tamil is an evergreen tree which possess medicinal value. It shows anti oxidant, antimicrobial, anticaries, immune-modulatory, antidiabetic, antiulcer, antifungal activity. All parts of the plant are used for medical purpose. The plant is useful, internally as well as externally. Used externally as a powder by itself, it arrests the bleeding in gums. The decoction is an effective gargle in sore throat, cough and hoarseness of voice. The paste is beneficial, externally used in skin disease ${ }^{7-12}$. The aim of this study was to determine the concentrations of heavy metals in Acacia catechu leaf extract and to estimate their contribution to the consumption by mankind.

\section{MATERIALS AND METHODS \\ Plant Material}

Acacia catechu ethanolic leaf extract-Authentic sample obtained from Green chem herbal extracts and formulations, Bangalore, India.

Methodology A) Analysis of Arsenic by Atomic Absorption
Spectrophotometer

Instrument parameters

Instrument: Atomic Absorption Spectrophotometer

Model No: AA-6300

Make : Shimadzu

Method : Graphite Furnace.

Lamp: Arsenic EDL Lamp (Electron Discharge Lamp)

Wavelength: $193.70 \mathrm{~nm}$.

Flame Type: Off.

Fuel gas : $5.5 \mathrm{~L} / \mathrm{min}$ [Argon].

Support gas: $15.0 \mathrm{~L} / \mathrm{min}$ [Air].

\section{Determination of Arsenic by AAS \\ Stock Solution}

Arsenic Standard solution $1000 \mathrm{mg} / \mathrm{L}(1000 \mathrm{ppm})$ as in $0.1 \mathrm{M}$ HCL

\section{Standard solutions}

From the stock solution prepare different dilutions of 5.0,10,15,20,25 ppm solutions using 0.1M HCL As, stored at $5^{\circ} \mathrm{C}$.

\section{Sample solutions}

Preparation of test solution

Weigh accurately $2.0 \mathrm{~g}$ of Acacia catechu ethanolic leaf extract (obtained from Company which make this formulation according to their formula) of standard volumetric on the flask-top, macerate overnight, heat to slake on the electric hot plate, keep somewhat-boiling, if brownish- 
black in colour, add again a quantity of the above mixture, continuously heat till the solution becomes clear and transparent, then raise temperature, heat continuously to thick smoke, till white smoke disperse, the slaked solution becomes colorless and transparent or a little yellow, cool, transfer it into a $25 \mathrm{ml}$ volumetric flask, wash the container with $0.5 \%$ Hydrochloric acid solution (HCL), add the washing solution into the same volumetric flask and dilute with the same solvent to the volume, shake well. Prepare synchronously the reagent blank solution according to the above procedure.

\section{Determination}

Weigh accurately about $2.0 \mathrm{~g}$ of Sample and digest it with $25 \mathrm{ml}$ of $0.1 \mathrm{M}$ HCL Mix properly and heat on a water bath for 15 minutes. Filter the sample and make up with $25 \mathrm{ml}, 0.1 \mathrm{M}$ HCL. Aspirate blank, standards and sample solutions separately by using above parameters.

\section{Calculation}

Actual Concentration $=$ Concentration $\times$ VF $\times$ DF $\times[C F / W F]$.

B) Analysis of cadmium by atomic absorption spectrophotometer

Instrument parameters

Instrument: Atomic Absorption Spectrophotometer

Model No : AA-6300

Make: Shimadzu

Method: Flame Continuous.

Lamp: Cadmium EDL Lamp (Electron Discharge Lamp)

Wavelength: 228.80nm.

Flame Type: Air-Acetylene.

Fuel gas : $2.5 \mathrm{~L} / \mathrm{min}$ [Acetylene].

Support gas: $15.0 \mathrm{~L} / \mathrm{min}$ [Air].

\section{Determination of cadmium by AAS}

Stock solution

Cadmium Standard solution $1000 \mathrm{mg} / \mathrm{L} \mathrm{Cd}$ in $0.5 \mathrm{M}$ Nitric acid

\section{Standard solutions}

From the stock solution prepare different dilutions of 1.0, 2.0, $3.0,4.0,5.0 \mathrm{ppm}$ solutions using $0.5 \mathrm{M}$ Nitric acid as, stored at $0-5^{\circ} \mathrm{C}$.

\section{Sample Solutions}

\section{Preparation of Test solution}

Reference to method of "Preparation of test solution" of $\mathrm{Pb}$

\section{Determination}

Weigh accurately about $2.0 \mathrm{~g}$ of Sample and digest it with $25 \mathrm{ml}$ of 0.5 Nitric Acid. Mix properly and heat on a water bath for 15 minutes. Filter the sample and make up with $25 \mathrm{ml}$, $0.5 \mathrm{M}$ Nitric acid. Aspirate blank, standards and sample solutions separately by using above parameters. Calculate the content of cadmium $(\mathrm{Cd})$ in the test solution from the calibration curve.

C) Analysis of lead by atomic absorption
spectrophotometer
Instrument parameters
Instrument : Atomic Absorption Spectrophotometer
Model No : AA-6300
Make : Shimadzu
Method : AA Flame
Lamp : Lead EDL Lamp (Electron Discharge Lamp)

Wavelength : $283.31 \mathrm{~nm}$.

Flame Type : Air-Acetylene.

Fuel gas : $2.5 \mathrm{~L} / \mathrm{min}$ [Acetylene].

Support gas : $15.0 \mathrm{~L} / \mathrm{min}$ [Air].

\section{Determination of lead by AAS}

Stock solution

Lead Standard solution $1000 \mathrm{mg} / \mathrm{L} \mathrm{Pb}$ in $0.5 \mathrm{M}$ Nitric acid

\section{Standard solutions}

From the stock solution prepare different dilutions of $5.0,10,15,20,25 \mathrm{ppm}$ solutions using $0.5 \mathrm{M}$ Nitric acid as, stored at $0-5^{\circ} \mathrm{C}$.

\section{Sample solutions}

\section{Preparation of test solution}

Weigh accurately $2.0 \mathrm{~g}$ of Acacia catechu ethanolic leaf extract (obtained from Company which make this formulation according to their formula) of standard volumetric on the flask-top, macerate overnight, heat to slake on the electric hot plate, keep somewhat-boiling, if brownishblack in colour, add again a quantity of the above mixture, continuously heat till the solution becomes clear and transparent, then raise temperature, heat continuously to thick smoke, till white smoke disperse, the slaked solution becomes colour less and transparent or a little yellow, cool, transfer it into a $25 \mathrm{ml}$ volumetric flask, wash the container with $0.5 \%$ nitric acid solution (HNO3), add the washing solution into the same volumetric flask and dilute with the same solvent to the volume, shake well. Prepare synchronously the reagent blank solution according to the above procedure.

\section{Determination}

Weigh accurately about $2.0 \mathrm{~g}$ of Sample and digest it with $25 \mathrm{ml}$ of 0.5 Nitric Acid. Mix properly and heat on a water bath for 15 minutes. Filter the sample and make up with $25 \mathrm{ml}$, $0.5 \mathrm{M}$ Nitric acid. Aspirate blank, standards and sample solutions separately by using above parameters.

D) Analysis of mercury by atomic absorption spectrophotometer

Instrument parameters

Instrument : Atomic Absorption Spectrophotometer

Model No : AA-6300

Make : Shimadzu

Method : Mercury Hydride System.(MHS)

Lamp : Mercury EDL Lamp (Electron Discharge Lamp)

Wavelength : $253.65 \mathrm{~nm}$.

Flame Type : Off.

Fuel gas : $5.5 \mathrm{~L} / \mathrm{min}$ [Argon].

Support gas : $15.0 \mathrm{~L} / \mathrm{min}$ [Air].

\section{Determination of Mercury by AAS}

Stock solution

Mercuric Standard solution $1000 \mathrm{mg} / \mathrm{L} \mathrm{Hg}$ in $1.5 \% \mathrm{v} / \mathrm{v}$ nitric acid

Standard solutions for caliberation curve

From the stock solution prepare different dilutions of 1.0, 2.0, 3.0, 4.0, $5.0 \mathrm{ppm}$ solutions using $1.5 \% \mathrm{v} / \mathrm{v}$ nitric acid. 


\section{Sample solutions}

\section{Preparation of Test solution}

Reference to method of "Preparation of test solution" of $\mathrm{Pb}$ in the above. Weigh accurately about $0.5 \mathrm{~g}$ of Sample and digest

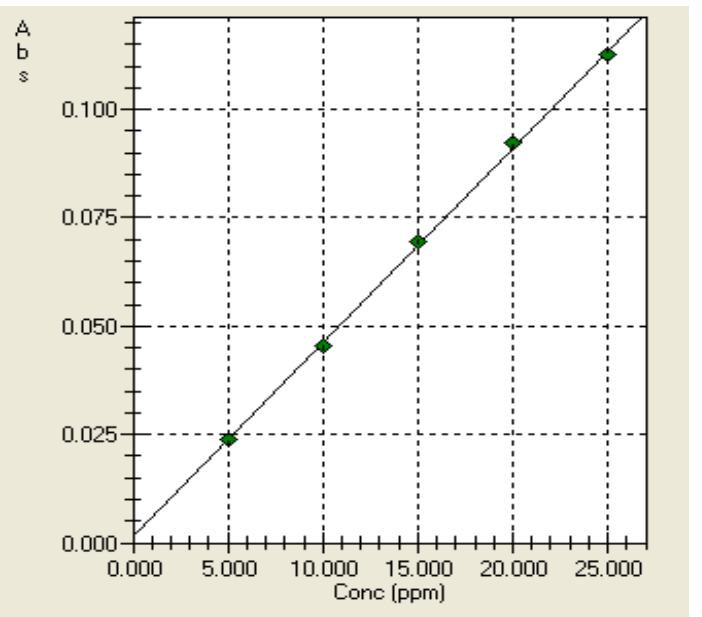

Figure 1: Estimation of Arsenic in Acacia Catechu Ethanolic Leaf Extract

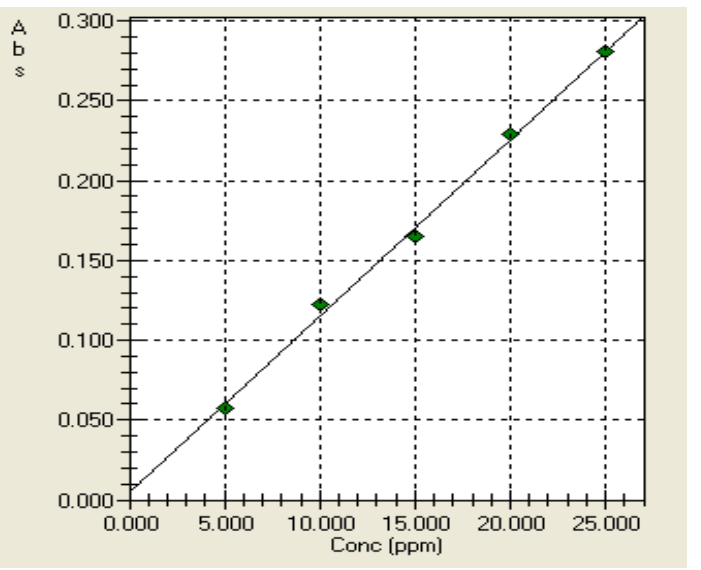

Figure 3: Estimation of Lead in Acacia Catechu Ethanolic Leaf Extract it with $50 \mathrm{ml}$ of $1.5 \% \mathrm{v} / \mathrm{v}$ nitric acid .Mix properly and heat on a water bath for 15 minutes. Filter the sample and make up with $100 \mathrm{ml}, 1.5 \% \mathrm{v} / \mathrm{v}$ nitric acid. Aspirate blank, standards and sample solutions separately by using above parameters.

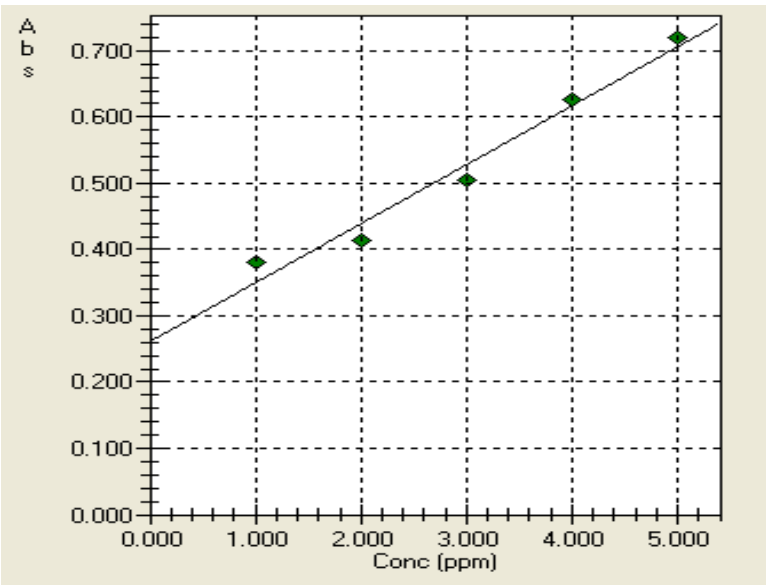

Figure 2: Estimation of Cadmium in Acacia Catechu Ethanolic Leaf Extract

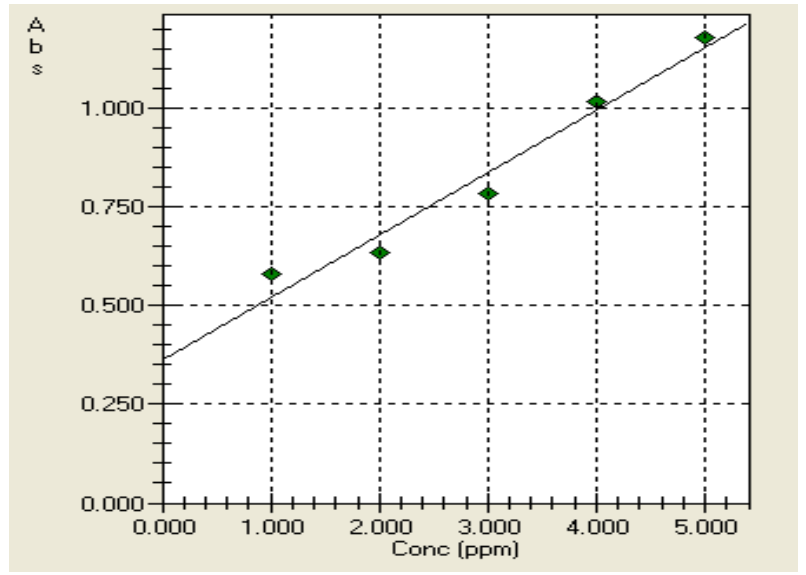

Figure 4: Estimation of Mercury in Acacia Catechu Ethanolic Leaf Extract

Table 1: heavy metal analysis of Acacia catechu ethanolic leaf extract

\begin{tabular}{|c|c|c|}
\hline Heavy metal & Permissible limit (ppm) & Observed value (ppm) mean \pm SD \\
\hline Arsenic $(\mathrm{AR})$ & Not more than $2 \mathrm{ppm}$ & $0.0008 \pm 0.039$ \\
\hline Cadmium $(\mathrm{Cd})$ & Not more than $1 \mathrm{ppm}$ & $0.0004 \pm 0.029$ \\
\hline Lead $(\mathrm{Pb})$ & Not more than $3 \mathrm{ppm}$ & $0.002 \pm 0.045$ \\
\hline Mercury $(\mathrm{Hg})$ & Not more than $1 \mathrm{ppm}$ & $0.0002 \pm 0.002$ \\
\hline
\end{tabular}

\section{RESULT AND DISCUSSION}

The results analysis of the levels of heavy metal present in the selected herbs is discussed in this section and the concentration of $\mathrm{AR}, \mathrm{Cd}, \mathrm{Hg}$ and $\mathrm{Pb}$ in the herbs is presented in (Table 1) the heavy metals analysed in the herbal extract is less than the permissible limits. ${ }^{16}$ The levels of heavy metals present in the extracts were expressed as mean of heavy metal concentration (ppm) \pm S.D of three replicates. Calibration functions for each element was determined. Concentrations of each heavy metal in the medicinal herb were calculated from the calibration functions. Statistical analysis is done in the herbal extract and there is no significant heavy metal present in it. The mean \pm SD is used to determine the t- value. For all the four heavy metals the null hypothesis was retained because the calculated $t$-value is less than the critical $t$-value at $p=0.05$. Figure 1 to 4 shows the standard linearity graph of the standard and test sample.

\section{CONCLUSION}

It is concluded from the present study that, heavy metal analysis of Acacia catechu ethanolic leaf extract obtained below standard prescribed limits In future each and every manufacturing batches should be tested by this ways to ensure whether the limits of heavy metal under control or not. Lead, cadmium, mercury are considered as non-essential heavy metals. The concentration of heavy metals (PPM) in the plant extract was found to be as Arsenic (0.0008ppm), Cadmium (0.004ppm), Lead (0.002ppm) and Mercury 
(0.0002ppm) respectively. From the results obtained it was concluded that levels of heavy metals fall within the permissible range and can be preferred to consume by mankind for various medicinal purpose.

\section{REFERENCES}

1. Celik A, Kartal A, Akdogan A, Kaska Y. Determining the heavy metal pollution in Denizli, Turkey by using Robinio pseudo-Acacia L. Environmental International 1995; 31: 105-112. http://dx.doi.org/1 0.1016/j.envint.2004.07.004 PMid:15607784

2. Neema NK et al. Determination of trace and heavy metals in some commonly used medicinal herbs in Ayurveda. Toxicol Ind Health; 2012. http://dx.doi.org/10.1177/0748233712468015 PMid:23222691

3. Radwan MA, Salama AK. Market basket survey for some heavy metals in Egyptian fruits and vegetables. Food Chem Toxicol 2006; 44: 1273-8. http://dx.doi.org/10.1016/j.fct.2006.02.004 PMid:16600459

4. WHO. Cadmium environmental health criteria.Geneva: World Health Organization; 1992: 134.

5. WHO. Lead environmental health criteria. Geneva: World Health Organization; 1995: 165.

6. Steenland K, Boffetta P. Lead and cancer in humans: where are we now? Am J Ind Med 2000; 38: 295-9. http://dx.doi.org/10.1002/10970274(200009)38:3<295::AID-AJIM8>3.3.CO;2-C

7. T Lakshmi. Black Cutch (Acacia Catechu Willd) -A Potent Medicinal Plant. Internationale Pharmaceutica Sciencia 2011; 1(2): 1-3.

8. T Lakshmi, RV Geetha, Roy Anitha. Acacia catechu willd -A pharmacological Review. International Journal of Current Research and Review 2011; 3(5): 101-111.
9. Wallis TE. Textbook of Pharmacognosy, 5thed, CBS Publishers and Distributors, New Delhi; 2005. p. 461-463

10. RV Geetha, Roy Anitha, T Lakshmi. In vitro evaluation of Anti bacterial activity of heartwood extract of Acacia catechu on oral microbes. International Journal of current research and review 2011;3(6): 4-9.

11. Trease E, Evans WC. Pharmacognosy. 13thed. London: Billiare Tindall; 1989. p. $61-2$

12. Okalebo JR, KW Catha and PL Woomer. Laboratory methods of soil and plant analysis: A working manual, TSBF-CIAT and SACRED Africa, Nairobi, Kenya; 2002. p. 200

13. Vaikosen EN and GO Alade. Evaluation of pharmacognostical parameters and heavy metals in some locally manufactured herbal drugs. Journal Chemical and Pharmaceutical Research 2011; 3(2): 88-97.

14. Parmar Saurabh, Shah Kinjal, Shah Nihar. Heavy Metal and Microbial Analysis Of Zymodyne Syrup- A Poly Herbal Formulation. AJPSR 2011;1(4): 46-53.

15. FAO/WHO, Contaminants. In Codex Alimentarius, vol. XVII, Edition 1. FAO/WHO, FAO/WHO, Codex Alimentarius Commision, Rome; 1984.

16. Fuh $\mathrm{C}, \mathrm{H}$ Lin and $\mathrm{H}$ Tsai. Determination of Lead, Cadmium, Chromium and Arsenic in 13 Herbs of Tocolysis Formulation Using Atomic Absorption Spectrometry. Journal of Food and Drug Analysis 2003; 11(1): 39-45.

Cite this article as:

Lakshmi.T, Rajendran.R, Antony silvester. Evaluation of heavy metals in Ethanolic leaf extract of Acacia catechu as indicator of pollution by Atomic absorption spectrophotometric (FAAS) analysis. Int. Res. J. Pharm. 2013; 4(6):109-112 